\title{
HILGARDIA
}

A Journal of Agricultural Science Published by the California Agricultural Experiment Station

CONTENTS

DEVELOPMENT OF THE FLOWER AND MACROGAMETOPHYTE OF

\section{ALLIUM CEPA}

H. A. JONES AND S. L. EMSWELLER

\section{ONTOGENY AND STRUCTURE OF COLLENCHYMA AND OF VASCULAR TISSUES IN CELERY PETIOLES}

KATHERINE ESAU

VESSEL DEVELOPMENT IN CELERY

KATHERINE ESAU 


\title{
HILGARDIA • VOLUME 10, NUMBER 11 DECEMBER, 1936
}

DEVELOPMENT OF THE FLOWER AND MACROGAMETOPHYTE OF ALLIUM CEPA

H. A. JONES AND S. L. EMSWELLER

\author{
ONTOGENY AND STRUCTURE OF \\ COLLENCHYMA AND OF VASCULAR TISSUES \\ IN CELERY PETIOLES \\ KATHERINE ESAU
}

VESSEL DEVELOPMENT IN CELERY

KATHERINE ESAU 



\section{VESSEL DEVELOPMENT IN CELERY}

KATHERINE ESAU 



\title{
VESSSEL DEVELOPMENT IN CELERY ${ }^{1}$
}

\author{
KATHERINE ESAU ${ }^{2}$
}

\section{INTRODUCTION}

BotANICAL LITERATURE contains comparatively little information concerning the development and breakdown of end walls in vessels, and, moreover, the available descriptions show a surprising lack of agreement with regard to the sequence of events in the establishment of continuity between vessel elements. This circumstance prompts the writer to report the observations on vessel end walls that were made incidentally to an earlier anatomical study (Esau, 1936) ${ }^{3}$ on petioles of the celery (Apium graveolens L.).

As in the previous investigation, the material was killed in a chromoacetic-formalin solution, was washed and dehydrated in dioxan, and embedded in paraffin. Heidenhain's haematoxylin and a combination of aniline blue and safranine were employed in staining the sections.

\section{DEVELOPMENT AND BREAKDOWN OF VESSEL END WALLS}

Structure of End Walls in Very Young Vessels.-In the ontogeny of vessels the mother cells expand and vacuolate before the secondary thickenings develop on their longitudinal walls. Very young mother cells have uniformly thin walls (fig. 1, below). When the cell reaches its mature diameter but still contains a nucleus and cytoplasm, its longitudinal walls are thin, whereas the transverse end walls are characteristically thickened (fig. 1, above). This thickening, which in longitudinal sections of cells appears lenticular in shape, occurs only on that portion of the end wall which is to be removed during maturation of the vessel, whereas the rest of the end wall is thin.

In prepared sections the thickened portion of the end wall usually appears to be limited above and below by two sharp, dark lines enclosing between them a lighter-colored substance. Plates $2, A$ and $4, A$ illustrate this condition. They also show the thin marginal region of the end wall.

Not infrequently a line is perceptible in median position in the thickened portion of the end wall. It seems to separate the thickening into two layers (plate $4, K$ ).

${ }^{1}$ Received for publication September 1, 1936.

2 Junior Botanist in the Experiment Station.

${ }^{3}$ See "Literature Cited" at the end of the paper for complete data on citations, which are referred to in the text by author and date of publication. 
Although studies on vessels reported here do not suffice for conclusions regarding the nature of the thickened portion of the end wall, the suggestion might be made that the thickening is primary in nature, similar perhaps to the torus thickening in bordered pits. The line dividing the thickening in two halves in some sections might be-using Kerr and Bailey's classification (1934) - the intercellular substance.

Ontogenetically this thickening is not related to the secondary wall that later appears in vessels; and its staining reactions seem to correspond to those of the primary wall. A particularly good contrast between the end wall and the secondary deposits on vessel walls may be obtained

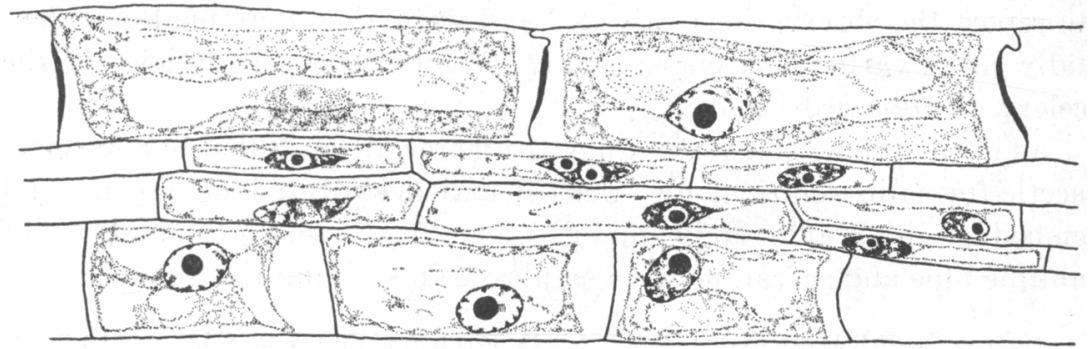

Fig. 1.-Longitudinal section from the primary xylem showing two rows of xylem mother cells and young xylem parenchyma between them. $(\times 590$.

with aniline blue and safranine. The latter is retained by the lignified secondary thickening, whereas a bright blue color is obtained in the primary part of the longitudinal walls and in the entire end wall.

End Walls During Deposition of Secondary Walls.-After the end wall has been thickened, the vessel element develops secondary wall layers-spiral, scalariform, or reticulate. To illustrate these later stages of vessel development, spiral elements will be used.

The coils of the spirals are deposited not only upon the longitudinal walls but also upon the thin portion of the end wall. Plate $2, B$ shows this condition in considerable detail. The coils of the spiral seen in optical cross section appear as knobs on the inner surface of the primary walls. Two coils were deposited on each side of the thin portion of the end wall, leaving the lenticular thickening exposed. Thin threads of the parietal cytoplasm appear above and below the end wall. The nucleus of one of the elements is discernible at the left below.

The same section as in plate $2, B$ has been used for the drawing in plate $4, D$. Two young elements with immature secondary walls are shown in their entirety in plate $3, A$ and $B$. Nuclei occupy central positions in the cells, and the end walls appear thick and dark.

In the first protoxylem vessels no coils are laid over the end wall; and 
the thin portion of this wall is, correspondingly, very narrow (plate $4, A$, $B$, and $C$ ). It is wider when one or more coils are deposited on the end wall (plate $4, D$ ). In some of the later protoxylem or in the metaxylem elements only a comparatively small area of the end wall becomes perforated, in which case the lenticular thickening is of a very limited extent (plate $4, J$ ).

Sometimes the two superimposed vessel elements do not begin the secondary-wall development simultaneously, but one lags behind the other (plate $4, B$ ).

The end wall is readily discerned in transverse sections of xylem. It obstructs the light no less than parenchyma walls when these are seen in face view. In plate 1 both photographs show, at the right, closed vessels with lumina darkened by the transverse end walls. In both these vessels one coil of secondary thickening is lying over the end wall. Open vessels appear at the left in each photograph. Plate $1, B$ also shows, at the lower right, a young vessel element with a parietal layer of cytoplasm and immature secondary wall. It has been cut away from either of its two end walls.

Plate 4, $L$ represents an end wall of an immature vessel. The lenticular thickening seen from above is darker than the thin margin. Faint lines appear to radiate from a barely perceptible ring on the end wall. Although the nature and significance of the radiating lines are not understood, the faint ring is secondary-wall material that is being deposited on the end wall.

Very frequently coarse granules or flakes of disintegrating cytoplasm obscure the visibility of end walls in transverse sections (plate $1, B$ ). Sometimes, however, the cytoplasm is removed in cutting, and the end wall is exposed to view (plates $1, A$ and $4, L$ ). In such cases the end wall usually shows numerous small dark spots on a lighter background. Sectional views of the end wall seem to indicate that these spots are granules on the surface of the wall (plate $4, D$ ).

In many sections the end wall is broken in cutting on the microtome. In such cases the fragments may become tilted (plate $4, M$ ).

The cytoplasm of developing vessels manifests a notable behavior. In vessel mother cells it shows considerable shrinkage in the fixed material (fig. 1 ; and plates $1, B ; 2, A ; 4, A$ ), but as development progresses it gradually loses this tendency to shrink. In $B$ of plate 4 the cytoplasm in the lower element receded only slightly from the knobs of secondary thickening, and its outline shows serrations corresponding to the intervals between the knobs. In 4, $C$ the cytoplasm adheres to the longitudinal walls, whereas in $4, D$ it is close to the end wall also. As was mentioned 
in the previous paper (Esau, 1936), sieve tubes show a similar decrease in tendency to shrink in progressively older elements.

Breakdown of End Walls.-The vessel end wall breaks down when the secondary wall is mature and the protoplast is ready to disappear. The end wall becomes thinner until but faint threads, like cobwebs, occur in its place and then vanish also. The thinning down of the end wall seems to indicate that it is dissolved.

In the early stages of this process the disintegrating cytoplasm, which stains very dark, usually obscures the clearness of the picture. Such a condition is shown in plate $3, C$, where a very thin end wall is covered with a heavy layer of coarse disintegrating cytoplasm; $F, G$, and $I$ in plate 4 show final stages in the breakdown of the end wall.

Portions of mature spiral vessels are shown in plates $2 C, D$, and $4, E$. The protoplasts and the lenticular part of the end wall have disappeared. Whereas two coils of secondary thickening form the rim between two sections of vessels in plates $2, C$ and $4, E$, one coil forms it in plates $1, A$ and $2, D$.

The primary wall, which is clearly visible between the upper and lower coils of the rim in plates $2, D$ and $4, E$, is the thinner portion of the end wall that surrounded the lenticular thickening. By focusing up and down one can follow this primary wall all around the rim. This situation is indicated in plate $4, H$, which shows the same vessel as plate $4, E$, but as it appears at a lower focus. This primary wall is seldom discernible between the two adjacent coils, so that the sections of the pairs of coils of the rim seem to be detached from the rest of the wall (plates 2, $C$ and $4, E)$. The primary wall may also appear very faint between the coils of the spiral on longitudinal walls (plate $4, G$, left).

In a series of superimposed vessel elements the end walls disappear not simultaneously but one after the other, the process starting at one end of the vessel and progressing toward the other. Stages from an intact end wall to its complete absence may be found in one section of a vessel in which disintegration of end walls is in progress.

In plate $3, C$ the other end of the lower element had a thick end wall, while the other end of the upper element appeared as is shown in the photograph in plate $3, D$. Here the end wall was absent, but the degenerated cytoplasm was still present. $E, F$, and $G$ in. plate 4 represent a sequence of end walls in elements of the same vessel. The end wall following that shown in $G$ was still intact. One end of the lower vessel element in $4, I$ was closed; the other end of the upper element was free of endwall fragments. 


\section{DISCUSSION}

These observations on development and perforation of end walls in vessel elements in celery fail to agree with the description given by Priestley and his co-workers (1935) regarding vessel differentiation in several woody species of angiosperms. These authors place the actual perforation of the end wall at a very early stage in the development of the vessel mother cell, namely before secondary wall thickenings are initiated, although "pectin films are often left stretched across the perforated ends of the vessel segments" (Priestley, et al. 1935, p. 53). Because of these thin mucilaginous films the protoplasts of individual elements do not mingle.

Still less similarity exists between the behavior of vessels in celery and vessel differentiation described by Scott (1935) in Ricinus, where these elements are said to pass through a coenocytic stage before secondarywall formation. This behavior in Ricinus is held by Scott to cause the development of long spirals continuous through many segments.

In celery the spirals are not continuous but show distinct breaks at the ends of each element. This break appears only as a change in the twist in earlier-formed vessels and as a rim, partly obstructing the pore, in vessels differentiating later in the development of a vascular bundle.

Vessel development in celery agrees in general features with that given for Robinia pseudoacacia by Eames and MacDaniels (1925, p. 151). These authors, however, show, in their figure 75, $C$, deposition of secondary wall on the part later to be removed. In the celery the thickening on the end wall appears to be primary and, as was suggested before, similar to the torus thickening in bordered pits.

Eames and MacDaniels (1925, fig. 75, D) also show the nucleus lying adjacent to the wall where dissolution is occurring. In the celery material the nucleus was usually found in median position in young differentiating elements (plate $3, A$ and $B$ ), but nearer one of the longitudinal walls in the more mature highly vacuolated cells (plate $2, B$ ). It was not observed at the end walls.

In view of the contrasting interpretation by different workers of the phenomena involved in vessel differentiation in angiosperms, further studies would be pertinent, particularly if combined with microchemical tests. 


\section{SUMMARY}

The primary vessels in celery show intact end walls until the elements are almost mature. These walls show a peculiar lenticular thickening in the region that later becomes the perforation.

Secondary thickenings are formed on longitudinal walls and usually also on the margins of the end wall around the lenticular thickening, leaving the latter exposed.

When the end wall breaks down, the lenticular thickening disappears gradually, as though dissolved. This change occurs after the secondary thickenings have been deposited. The protoplast disintegrates at the same time.

\section{LITERATURE CITED}

Eames, A. J., and L. H. MacDaniels.

1925. An introduction to plant anatomy. 364 p. MeGraw-Hill, New York.

EsAU, K.

1936. Ontogeny and structure of collenchyma and of vascular tissues in celery petioles. Hilgardia 10:431-476.

KeRR, TH., and I. W. BaIley.

1934. The cambium and its derivative tissues. No. X. Structure, optical properties, and chemical composition of the so-called middle lamella. Jour. Arnold Arboretum 15:327-49.

Priestley, J. H., L. I. ScotT, and M. E. Malins.

1935. Vessel development in the angiosperm. Leeds Phil. Soc. Proc. 3:42-54.

Sсотт, F. M.

1935. The cytology of the differentiating spiral vessel in Ricinus communis. Science 82:302. 

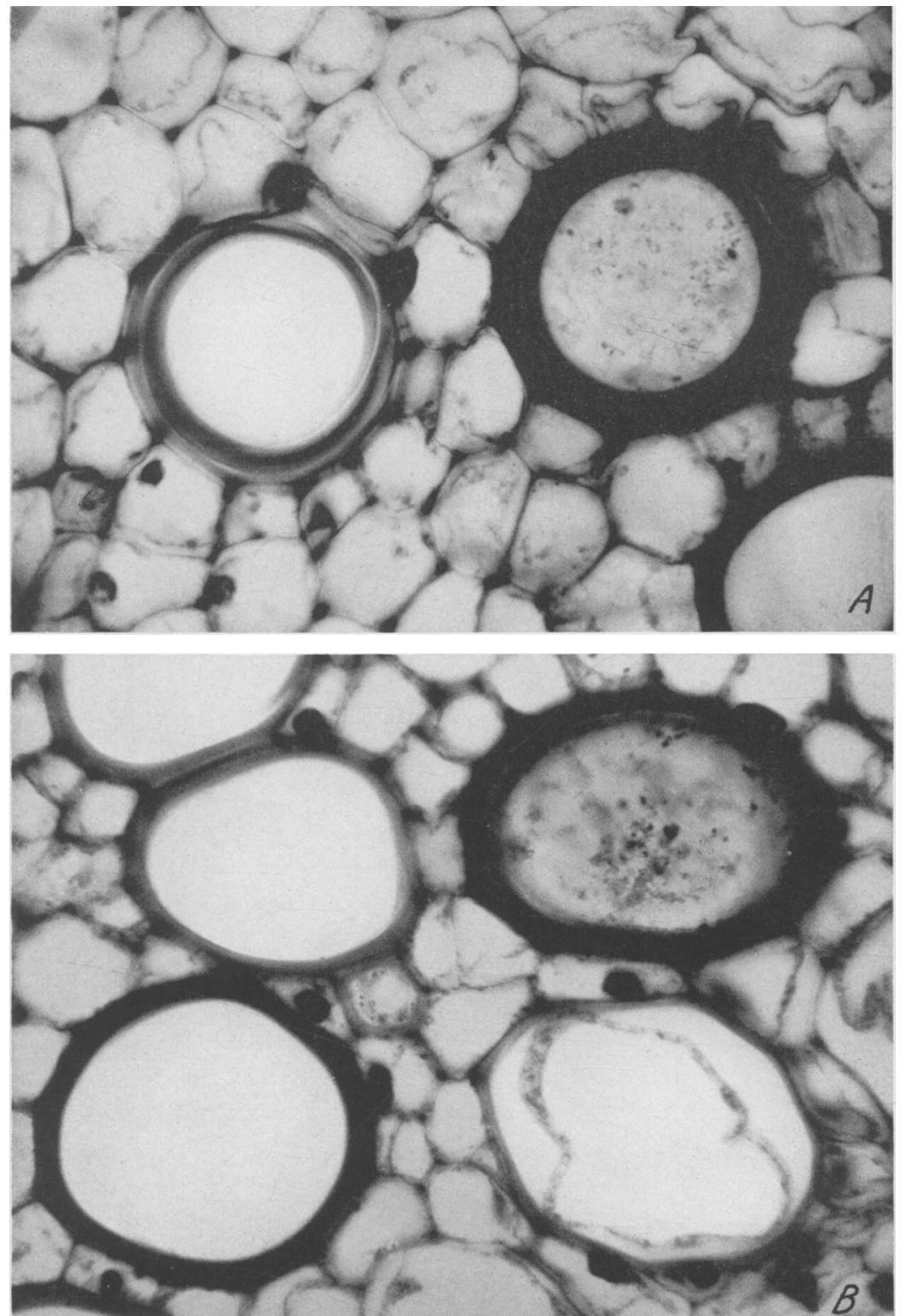

Plate 1.-Transverse sections of xylem showing contrast between immature and mature vessels: $A$, one immature vessel at the right showing intact end wall; $B$, two immature vessels at the right. The one at the upper right shows an intact end wall with flaky degenerating cytoplasm covering it; the other (lower right) has a parietal layer of cytoplasm and immature secondary thickening. ( $\times 833$.) 

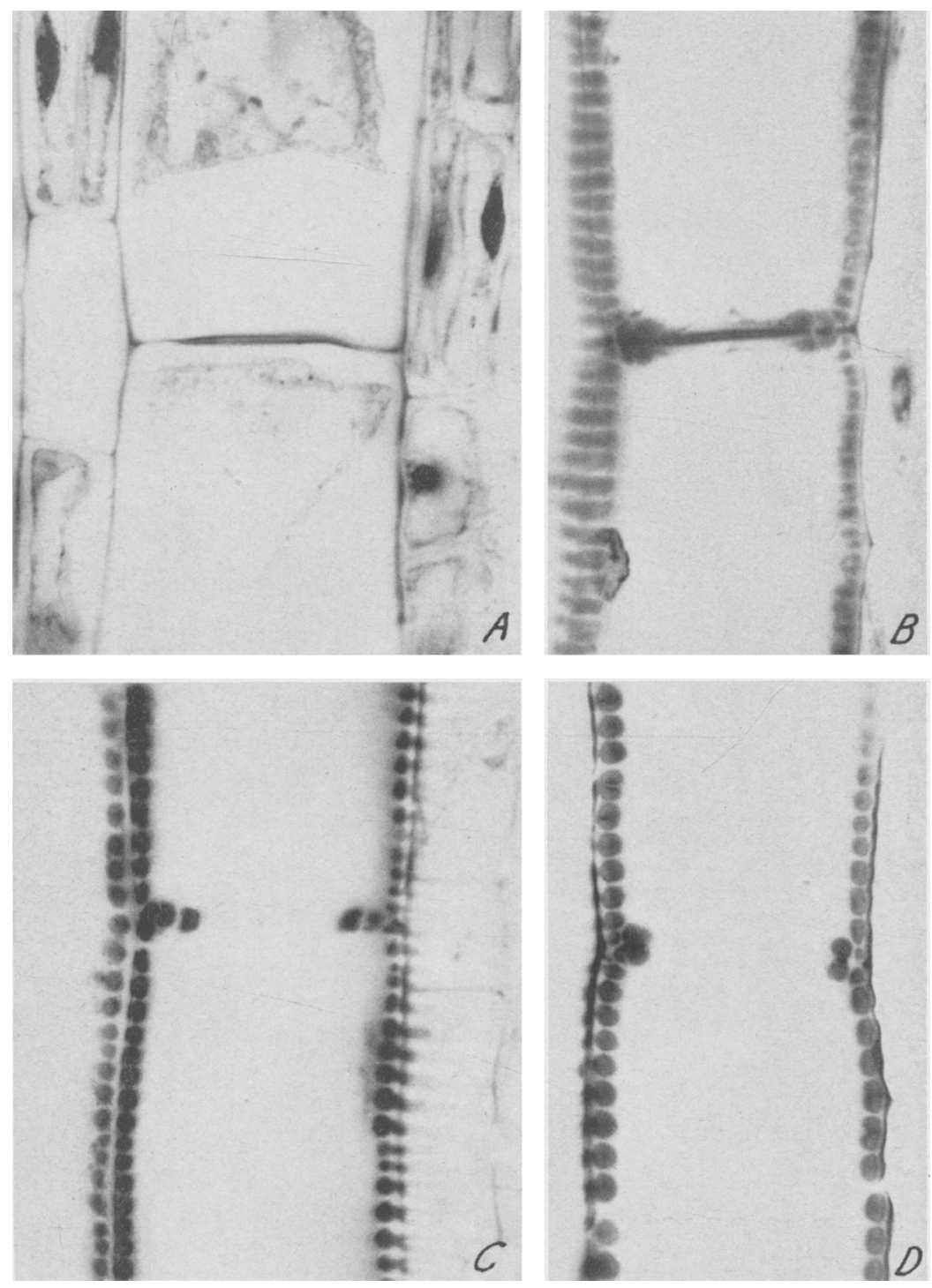

Plate 2.-Longitudinal sections of vessels cut through the union of two vessel elements: $A$, lenticular thickening on the end wall, but no spiral thickenings on the longitudinal walls; $B$, end wall still intact and spiral thickenings on longitudinal walls and on the thin portion of the end wall; $C, D$, mature vessels, the end wall having disappeared except for the portion covered by the rim of secondary thickening. ( $X 833$. 

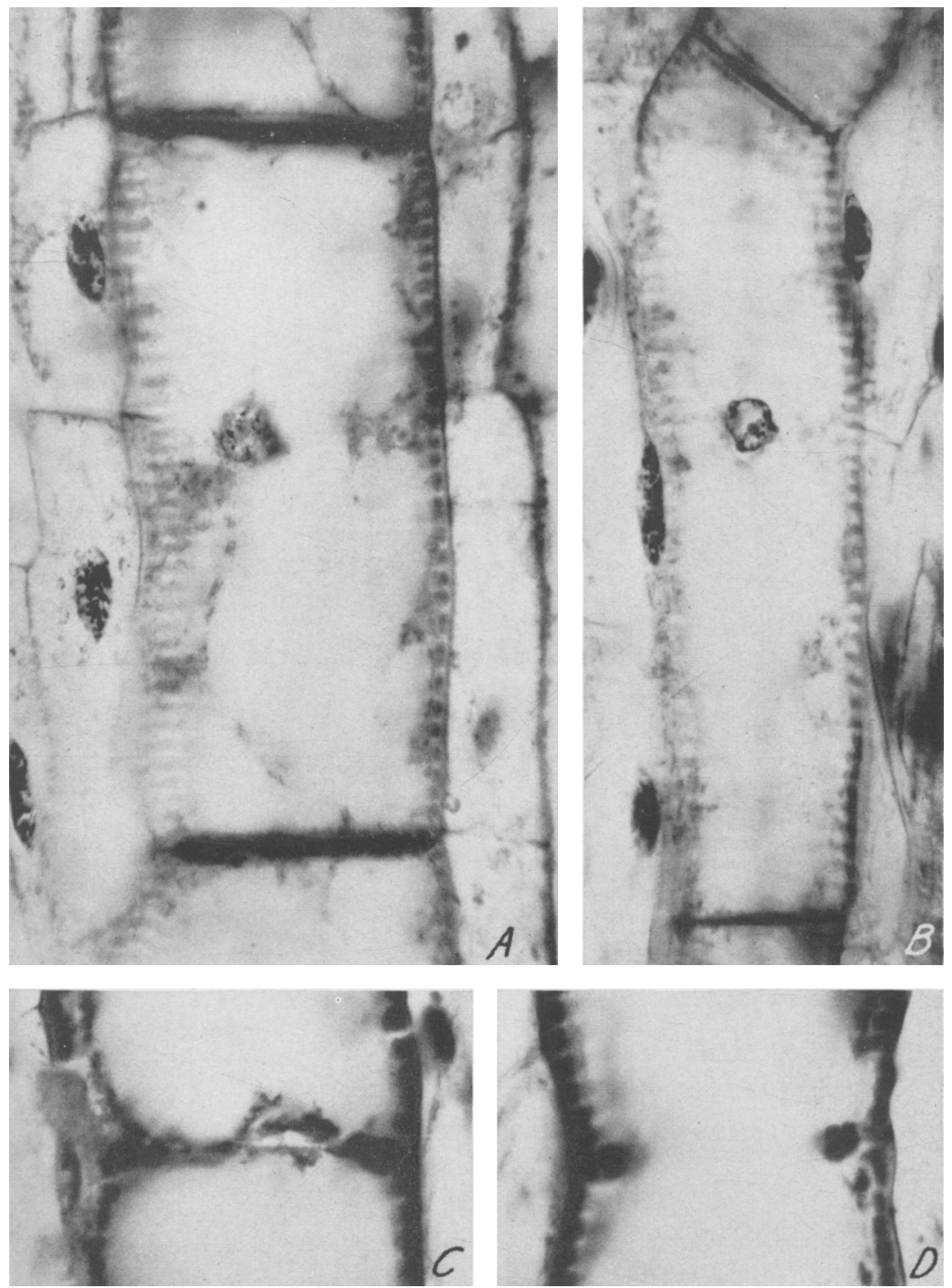

Plate 3.-A, B, Young vessel elements showing nuclei, thickened end walls, and immature spiral secondary thickenings. $C$, Disintegration of end wall between two vessel elements. $D$, Final stage in end-wall disintegration; the cytoplasm is still evident. (All longitudinal sec-
tions, $\times 833$.) 


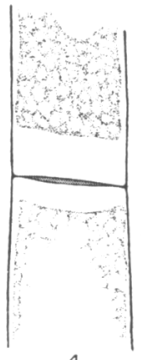

$A$

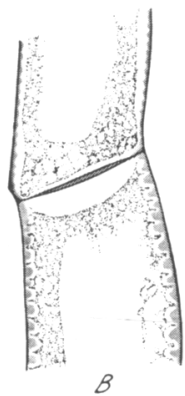

$B$
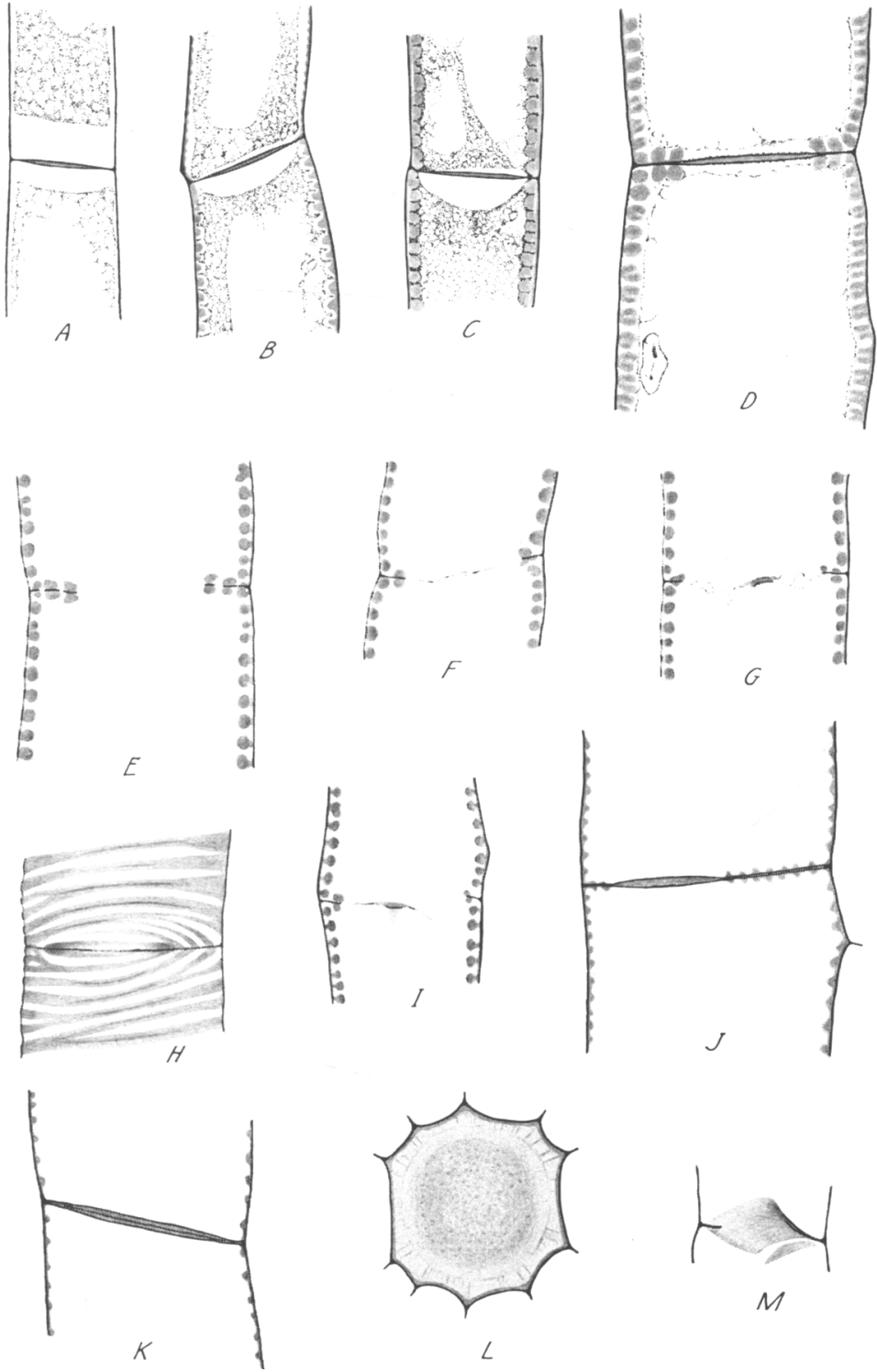

M

Plate 4.-Development and breakdown of the vessel end wall: $A-D$, show thickened end wall and successive stages of development of spiral secondary thickenings: $E, H$, rim between two mature vessel elements shown at two different focal planes; $F, G, I$, disintegration of the end wall; $J$, end wall of vessel elements that in a mature state communicate through a small perforation; $K$, shows the median line in the thickened end wall; $L$, end wall in face view; $M$, end wall broken in preparation. $(\times 700$. 